\title{
BIOGAS PRODUCTION FROM WASTE IN A SANITARY LANDFILL REACTOR
}

\author{
Assem Ali Aldrawsha ${ }^{1 *}$, Ahmedlsmail ${ }^{1}$, Rajamohan Natarajan², Osama Ibrahim¹
}

\begin{abstract}
In this research study, the feasibility of waste to biogas conversion in a sanitary landfill unit was investigated. The academic work was about quantifying the methane emission values during the wet season, by applying the FOD method on a static flux chamber and a pilot-scale sanitary landfill, and the methane emission potential table was established. The study was conducted for a period of 16 weeks from November 2018 to February 2019. The waste used in the pilot-scale sanitary landfill included food and cattle waste. It was observed that the methane emission rate peaked at $0.25 \mathrm{~g} / \mathrm{m}^{2}$.d during week 10 and decreased to $0.12 \mathrm{~g} / \mathrm{m}^{2} . \mathrm{d}$ during week 16 . In addition, the carbon dioxide concentration obtained was $45 \%$ during the anaerobic phases and around $50 \%$ during the aerobic phases. The academic work studied the contribution of leachate $\mathrm{pH}$, waste moisture content, and gas temperature to change methane emission values. The waste moisture content proved to have a direct relationship with the methane emission values, unlike the gas temperature. The leachate $\mathrm{pH}$ value during week $10 / 5^{\text {th }}$ test day was found to be 7.92, and increased steadily throughout the remaining study period, even though the methane emission values decreased during that period (after week $10 / 5^{\text {th }}$ test day).It was observed that the leachate recirculation process decreased the leachate content even though it affected the methane emission values.
\end{abstract}

\section{Keywords: Methane, Emission, Yield, Landfill}

\section{INTRODUCTION}

Municipal solid waste (MSW) disposal by landfilling is the most utilized method for waste disposal[1,3,9,19,24]. Sanitary landfilling is a process of disposing of MSW - non-hazardous waste - on land without causing any disturbance to the surrounding environment [10,23,24]. Sanitary landfills differ from the regular dumping site with its lining system and its leachate and landfill gas collection systems [24]. The sanitary landfill's biological, physical and chemical processes results in the production of leachate and landfill gas (LFG) - the outcomes are produced through anaerobic conditions [4,24]. The sanitary landfills considered as a renewable bioreactor, it is considered as an ideal solution to risks related to MSW dumping, also, it is operationally a low-priced method of waste dumping $[4,8,17,24]$.

The sanitary landfill leachate is a liquid that percolates through the waste layer as soon as it is placed. The leachate contains organic, inorganic, and heavy metal compounds [9,16,17,24]. However, the recirculation of leachate in the landfill increases the rate of waste degradation that leads to an increase in LFG emission rates [21]. Recirculation of leachate is considered an inexpensive option for leachate management; the leachate recirculation enhances the biodegradation of the organic matter leading to a faster stabilization, reduces leachate quantity and filtrates the organic and inorganic content in the leachate [24]. The degradation stages involve the hydrolysis or aerobic degradation stage, the hydrolysis and fermentation stage, the acetogenesis stage, the methanogenesis stage, and the oxidation stage [23]. The presence of oxygen denotes aerobic conditions, while the absence of oxygen denotes anaerobic conditions [20,23]. The hydrolysis or aerobic degradation stage initiates as the waste is placed, and the aerobic micro-organisms degradation capabilities depend on the waste oxygen content. The carbon dioxide $\left(\mathrm{CO}_{2}\right)$ produced from this stage is either released as a gas, or absorbed in the water that is produced, and the amount of carbon dioxide that is absorbed causes the leachate to be acidic [5,23]. The hydrolysis and fermentation stage initiates as the oxygen is consumed- from the previous stage, which in turn conditions to anaerobic conditions. The main products of this stage are $\left(\mathrm{CO}_{2}\right),\left(\mathrm{H}_{2}\right),\left(\mathrm{NH}_{3}\right)$, and organic acids. The acetogenesis stage occurs under anaerobic conditions, the acetogen micro-organisms convert the organic acids produced from the previous stage to acetic acid, acetic acid derivatives, $\left(\mathrm{CO}_{2}\right)$ and hydrogen. The methanogenesis stage occurs under anaerobic conditions, the LFG

This paper was recommended for publication in revised form by Regional Editor Mohammad Ghalambaz

${ }^{1}$ Department of Engineering, Sohar University, Sohar, Oman

${ }^{2}$ Department of Engineering, Sohar University, Sohar, Oman

*E-mail address: assemali8@gmail.com,140779@soharuni.edu.om

Orcid id:0000-0002-0036-7916

Manuscript Received 17April 2020, Accepted 05 July 2020 
is generated in this stage, the produced LFG consists of approximately $60 \%$ methane $\left(\mathrm{CH}_{4}\right)$ and $40 \%\left(\mathrm{CO}_{2}\right)$ [23]. The methanogenic micro-organisms degrade the organic acids formed in the second and third stages, concurrently, the $\mathrm{pH}$ rises to $7-8$ or even 9 in some cases [20,23]. The oxidation stage marks the end of the degradation process, as the acids are used in the production of LFG main gases $\left(\mathrm{CH}_{4}\right.$ and $\left.\mathrm{CO}_{2}\right)$, and followed by a return to aerobic conditions. During this stage, the leachate $\mathrm{pH}$ steadies unlike the previous stages [23].

The sanitary landfill composes of a final cover system and a landfill liner system, aligned layer-by-layer. The final cover system hinders moisture from entering the sanitary landfill. It consists of a cover vegetation layer, a final cover layer, a working landfill system and a waste layer [25].

The final cover layer consists of a drainage layer, a hydraulic barrier and a foundation layer. The drainage layer aims to transport the infiltrated liquids outside the sanitary landfill. The hydraulic barrier precludes any movement of water into the sanitary landfill. The foundation layer serves as a protection layer, it consists of geomembrane and a low hydraulic conductivity soil. The working landfill system represents the low hydraulic conductive soil; the system consists of several different layers of natural fill material that have low hydraulic conductive soil, in order to perform various functions [26]. Regarding the research, the final cover system is comprised of compacted soil (low hydraulic conductive), which represents the working landfill system. The unit interior is made of Polyvinyl Chloride (Pvc), which serves as a protection layer (geomembrane). A tint is fixed above the unit functions similarly to a drainage layer, whereupon infiltration of rainwater is minimized.

Waste is shredded, mixed, and compacted before placement, to ensure that the landfill's capacity is fulfilled, to reduce odours, and to reach the desired layer thickness. The waste's density inside the landfill depends on the degree of pre-compaction of the waste $[23,26]$. With respect to the research, the waste was shredded, mixed, compacted, and then placed. The waste mixture placed comprises of food and cattle waste.

The landfill liners systemic a mix of liner materials and leachate's collection layers that are placed below the waste layer, with purposes of collecting and containing leachate. The liner system has four types: single liner system, composite liner system, double liner system and multiple liner system. The four systems involve a drainage system/leachate collection system that consists of a series of perforated pipes surrounded by gravel to protect it from crushing due to overload pressure. The drainage system/leachate collection system is linked to a holding tank; the leachate is either disposed or chemically treated. In addition, the four systems involve a separation and protection layer, which is a double layer of geotextile, with geomembrane installed between the geotextile layers. The layer aims to minimize the amount of precipitation flowing into the landfill, ensuring efficient collection of leachate and controlling the accumulation and migration of LFG. The single liner system composes of a drainage system/leachate collection system, a separation and protection layer, and a soil foundation. The composite liner system layers are similar to the single liner system layers, except that a secondary layer of clay is set below the geomembrane. The double liner system is a doubled single liner system separated by a drainage system layer. The multiple liner system functions in a similar to the double liner system, the layers above the drainage system functions in a similar to the composite liner system, while the layer underneath it functions in a similar way to the single liner system [23]. Regarding the research, the landfill liner system type used in the pilot-scale sanitary landfill is the single liner system, which is the most suitable type to use since any contamination of leachate will affect the environment slightly [23]. The system used composes of a drainage system/leachate collection system surrounded by gravel for protection purposes. The unit interior bottom and sides are made of Pvc, which serves as a protection layer (geomembrane).

The LFG control and collection system is a grid of perforated pipes installed above the waste layer linked to solid pipes extending through the upper landfill layers that are linked to a gas collection header [22]. With respect to the research, the static flux chamber was used to quantify and collect the LFG.

The static flux chamber method, unlike the dynamic flux chamber method, is characterized by its ease and direct use for measurements $[14,15]$. The flux chamber is a box or a dome, made of aluminum, stainless steel, or various types of plastics $[13,14,20]$. The flux chamber is provided with a gas carrier and temperature/moisture detectors [20]. Regarding the research, the flux chamber used is static and it is made of Pvc. It is provided with a thermometer, a moisture meter, a propeller, and a gas carrier linked to the sampling bag.

The first order decay (FOD) method is a technique developed by the intergovernmental panel on climate change organization, the technique provides realistic estimate of emission from landfills, also, it is recommended by the United States environmental protection agency (EPA). The model is considered as one of the most significant and 
widely used models for the quantification of $\left(\mathrm{CH}_{4}\right)$ emission from landfills [14]. Throughout the study period, the FOD model was applied to quantify $\left(\mathrm{CH}_{4}\right)$ emission and $\left(\mathrm{CO}_{2}\right)$ concentration proportions originating from the pilotscale sanitary landfill.

Due to the increase of consumption of natural resources and the exponential increase in world population, the MSW quantity have highly increased [2]. Currently MSW makes 70\% of all total waste [11]. In the Gulf countries, the waste generation rate per capita are the highest globally, reaching around 120 million tons per year [18]. As the waste is generated from different sources, a sorting and separating method is always vital due to the waste heterogeneity [7].

Sohar is the largest city of the Al Batinah North Governorate in Oman. With the increase in population, and the development of modern residential, commercial and industrial sectors, there is an influx of MSW, and thus a MSW landfill is required to cover energy needs and conserve the solid remnants. The potential table designed based on the pilot-scale landfill can be further used to design a sanitary landfill and to get the energy outcome from it as a quantity. The LFG collected is considered as an energy source and can be used to minimize the use of other common energy sources [6]; the extracted LFG can then be used to generate electricity [12].

In this study, a novel study was about applying the FOD model on a bioreactor that consists of two parts: a static flux chamber and a pilot-scale sanitary landfill, in order to quantify the methane emissions and the carbon dioxide concentration proportions. The academic work studied the contribution of leachate $\mathrm{pH}$, waste moisture content, and gas temperature to change methane emission values based on Sohar's climate. The methane emission values are used to design a methane emission potential table, which can then be further used to design a sanitary landfill based on population and waste per capita.

\section{THEORY}

\section{Bioreactor Description}

The bioreactor - experimental vessel - is a 100-gallon tank made of polyvinyl chloride (Pvc) as illustrated in figure 1, the layers inside the tank represents a pilot-scale sanitary landfill, whilst the closed void above the pilotscale sanitary landfill layers represents a static flux chamber.

The landfill reactor or the bioreactor height is $0.91 \mathrm{~m}$, and its diameter is $0.86 \mathrm{~m}$, the height of the landfill layers inside the bioreactor is $0.6 \mathrm{~m}$.

The pilot scale sanitary landfill is comprised of a final cover system made up of compacted soil, compacted waste layer, and a single landfill liner system. This single landfill liner system is made up of a drainage system/leachate collection system surrounded by gravel. The static flux chamber is provided with a thermometer, a moisture meter, a propeller, and a gas carrier linked to the sampling bag.

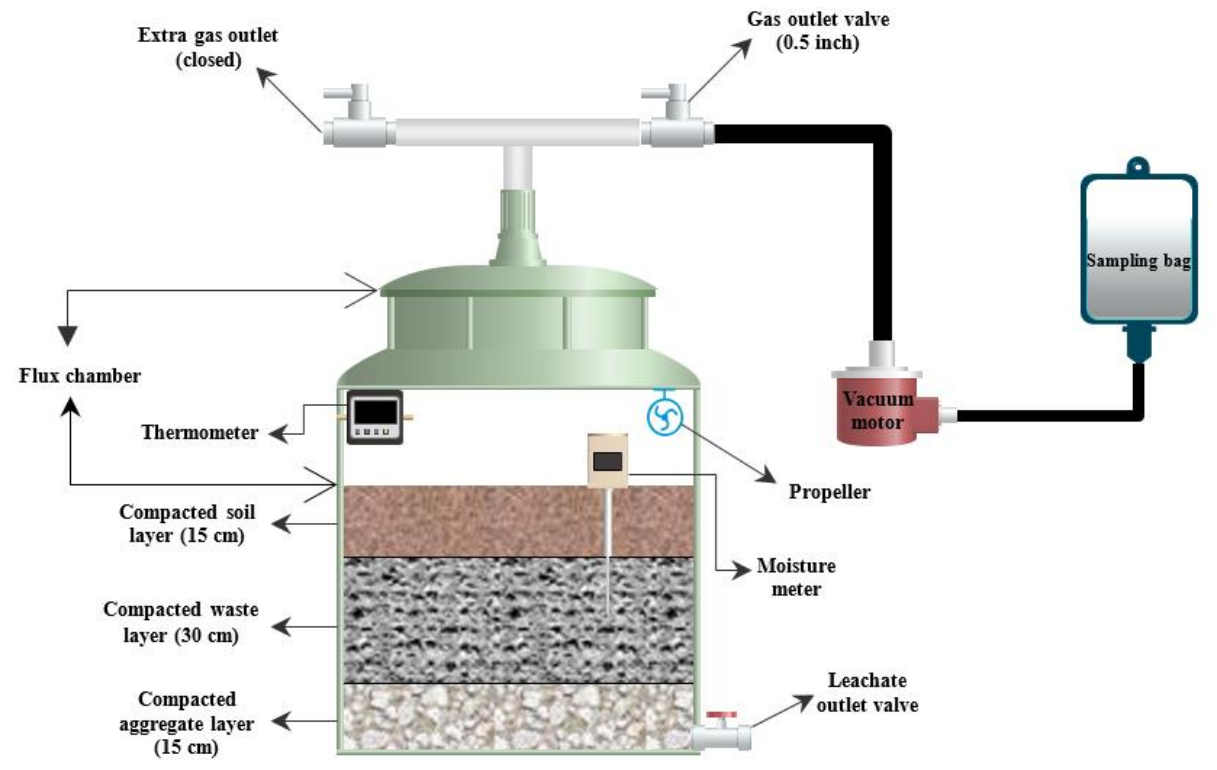

Figure 1. Landfill bioreactor 
The leachate extracted during the test is used for recirculation. However, throughout the study period, a tent installed above the bioreactor, minimized any rainwater seepage, provided shade, and reduced warming of the tank body $[13,14]$. The unit interior is made of Pvc which serves as a protection layer.

The pilot-scale sanitary landfill composes of three layers as shown in figure 2, with the final cover system being a layer of compacted soil. This system represents the working landfill system. The tint fixed above the unit functions similarly to a drainage layer, which minimizes the infiltration of rainwater. The waste layer consists of a mixture of water, and a combination of $70 \%$ food waste and $30 \%$ cattle waste, as these proportions are based on Sohar's landfill organic waste ratios. The total amount of waste mix is $250 \mathrm{~kg}$, its mix ratio distributed as cattle waste to water $(1: 1)$, and food waste to water (1:0.5). The single landfill liner system composes of a protection layer (geomembrane) represented by the unit interior which is made of polyvinyl chloride (Pvc), and drainage system/leachate collection system represented by a pipe linked to a leachate outlet valve; the part of the pipe that is inside the liner system is perforated. The drainage system/leachate collection system is surrounded by gravel for protection purposes. Soil foundation is not required since the unit does not allow any infiltration of leachate to the ground.

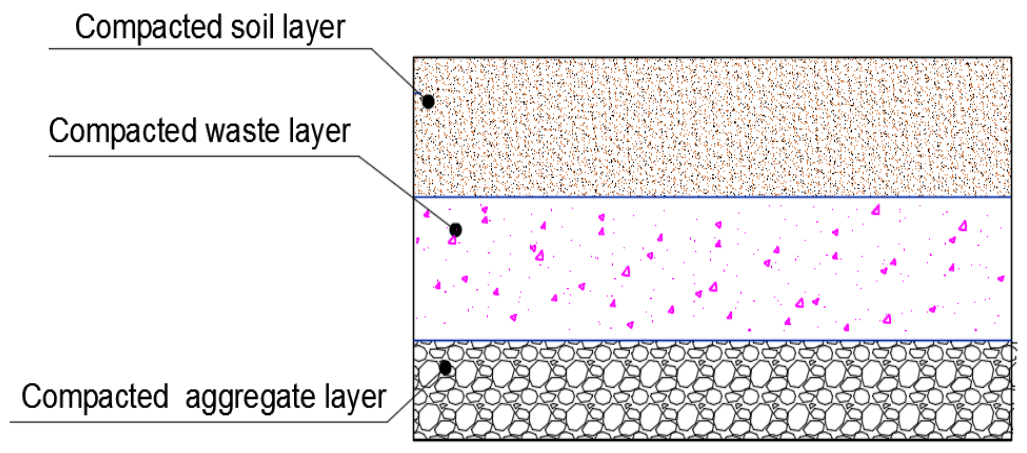

Figure 2. Pilot scale sanitary landfill layers

The static flux chamber is provided with a propeller, a gas carrier linked to the sampling bags, a thermometer, and a moisture meters illustrated in figure 3. The flux chamber is provided with a propeller to attain sufficient mixing of the gases during the test [13].

The gas carrier is basically a PvcT-section shaped pipe with a part linked to the sampling bags, while the other part is kept closed during the study period(the extra gas outlet is a precautionary measure). The part of Tsection that is linked to the sampling bags, is linked through a vacuum motor and a Pvc tube. A hole of 0.5 inch is drilled in the side to insert the thermometer wires. Foam is used to cover the holes entirely to prevent any leakages of LFG during the test.

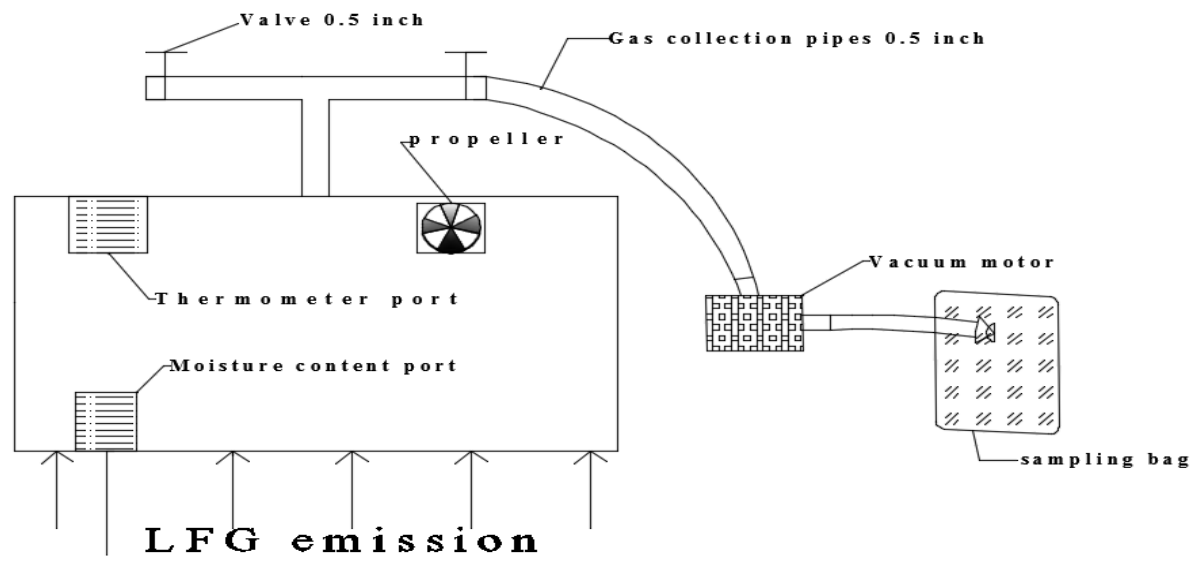

Figure 3. Static flux chamber 


\section{Experimental Method}

\section{Scope of work}

A brief summary of the work done is shown in Figure 4.

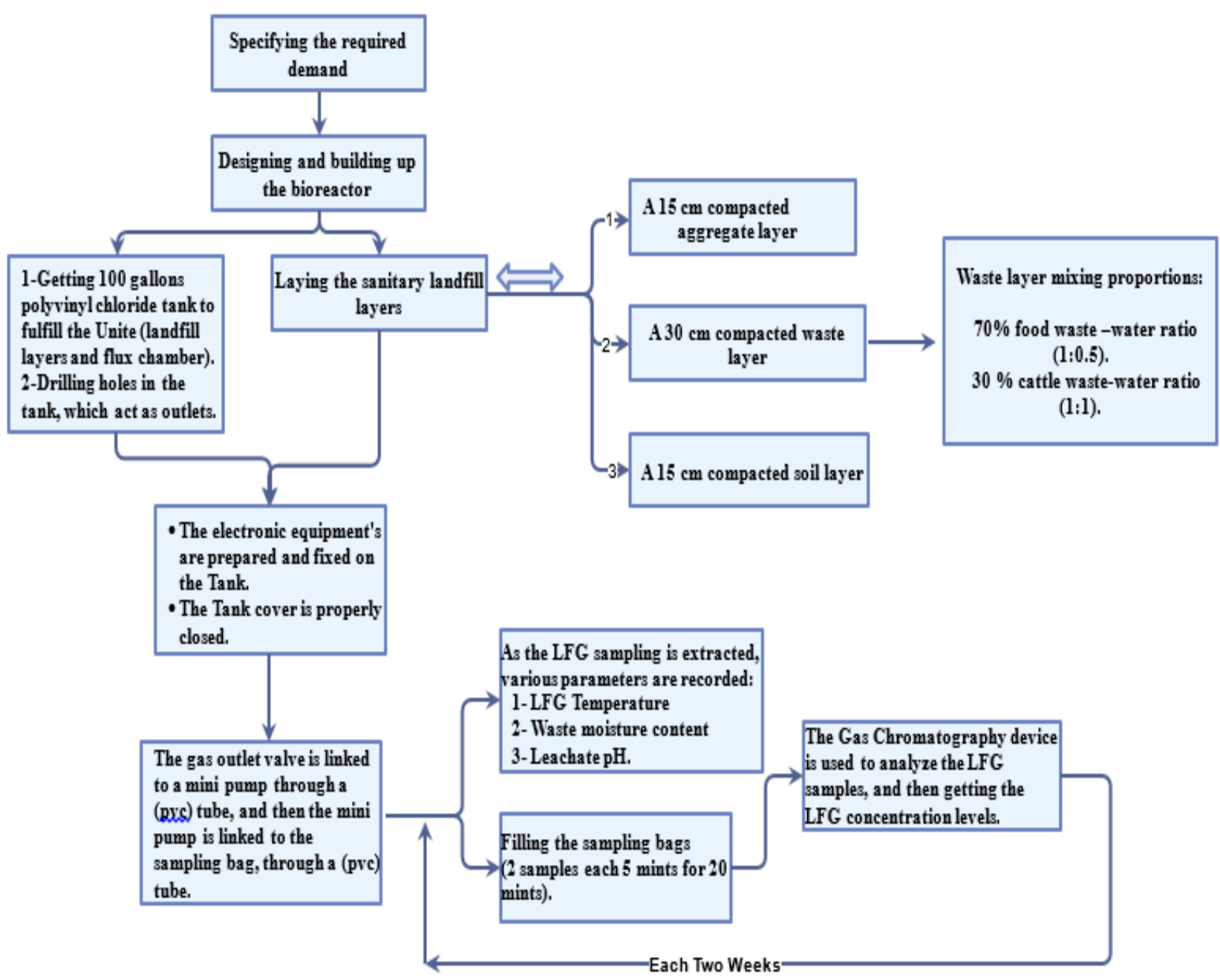

Figure 4. Sequence of experiments

\section{Preparation of Waste Layer Mixture}

Pre-placement-the waste was shredded, mixed, and compacted. The shredding and mixing processes were done manually using shovels while the pre-compacting process was done using a small-size compactor (25\% compaction). The waste mixture placed comprises of food and cattle waste. Post-placement - the waste was compacted, to get the desired layer thickness. As illustrated in section 2.1, the waste layer consists of a mixture of water and a combination of $70 \%$ food waste and $30 \%$ cattle waste. The total amount of waste mix is $250 \mathrm{~kg}$, mix ratio distributed as cattle waste to water (1:1), and food waste to water (1:0.5).

The numbers of mixtures made are three, with each involving different weight percentages as clarified in table 1 . The mixture weights are originally calculated in $\mathrm{kg}$; however, the units are converted to percentages in order to clarify the desired ratios of mixture. 
Table 1. Waste layer mixture proportions.

\begin{tabular}{|c|c|c|}
\hline \multirow{2}{*}{$\begin{array}{c}\text { Mix } \\
\text { No. }\end{array}$} & \multicolumn{2}{|c|}{ Weight (Percentage) } \\
\cline { 2 - 3 } & Cattle waste \% & Food waste \% \\
\hline 1 & $10 \%$ & $25 \%$ \\
\hline 2 & $10.6 \%$ & $26.3 \%$ \\
\hline 3 & $9.4 \%$ & $18.7 \%$ \\
\hline Total: & $30 \%$ & $70 \%$ \\
\hline
\end{tabular}

\section{Pilot Scale Sanitary Landfill Layers}

The pilot-scale sanitary landfill is composed of three layers as illustrated in section 2.1 ; the final cover system, the waste layer, and the single landfill liner system.

The working landfill system composes of natural fill materials with low hydraulic conductive soil; the system minimum layer thickness is $0.15 \mathrm{~m}$ [26]. With respect to the final cover system layer used in the pilot-scale sanitary landfill, the thickness taken is $0.15 \mathrm{~m}$, which is the minimum allowable thickness. The material placed in the layer is compacted soil.

The waste layer thickness post-placement was $0.4 \mathrm{~m}$, however, the layer experienced a $25 \%$ compaction, and hence the layer thickness became $0.3 \mathrm{~m}$. The $0.3 \mathrm{~m}$ layer thickness is suitable, since the used final cover system layer thickness is $0.15 \mathrm{~m}$ which is the minimum layer thickness [26].

The single landfill liner system is a $0.15 \mathrm{~m}$ thickness layer, it is mostly covered with aggregate, as the aggregate provides protection for the pipe - linked with a valve - that is used to collect and control the leachate. The pipe is made of Pvc. The aggregate used is brought from a mountain crusher, and has a diameter $20 \mathrm{~mm}$.

\section{Experimental Procedure}

The study was conducted for a period of 16 weeks, every two weeks four primary reading values were taken, in a total of eight test days. Each test day, four primary readings were taken; the interval between them is five minutes. However, each primary reading was taken twice to avoid human errors, and the average value between the values is taken as the primary reading value. The study was conducted during the wet season in Sohar, from November to February.

Several pre-experiment procedures are mandatory to be done during test days as precautions, and to avoid any type of human errors. With respect to the research, the sampling bags were cleaned, the gas carrier T-section pipe valves were closed properly, and a stopwatch was set for a five-minute interval between the four primary readings taken. The cleaning process was done by attaching the sampling begot a vacuum motor through a Pvc tube, then filling the sampling bag with oxygen and extracting it. The procedure is applied three times [13].

After that, the experimental procedure is initiated. The flux chamber gas outlet was linked to the sample bag. Then, the static flux chamber was placed on the pilot-scale sanitary landfill. Next, the gas outlet was opened. After filling the two sample bags, a five-minute interval was set using the stopwatch, and the whole process was repeated for the rest of the primary reading samples.

Both, the pre-experiment and experimental procedures were repeated each test day. The waste moisture contents and gas temperatures were measured simultaneously while taking the LFG sample with each primary reading, on every test day.

At the end of each test day, the leachate valve was opened; a sample of the leachate was taken for analysis to measure its $\mathrm{pH}$, while the rest of the extracted leachate was circulated inside the pilot-scale sanitary landfill. The LFG samples were analyzed using the Gas Chromatograph. The waste moisture content and LFG temperature were measured using the moisture meter and the thermometer, respectively. 


\section{Quantification of The Methane Gas Emission}

The first order decay (FOD) model shown in equation 1 is used to estimate the methane emission $\left(\mathrm{g} / \mathrm{m}^{2} . \mathrm{d}\right)$ $[13,14]$.

$$
F=P \cdot V \cdot M \cdot U \cdot\left[\frac{d c / d t}{A \cdot R \cdot T}\right]
$$

Where $\mathrm{P}$ is pressure $(1 \mathrm{~Pa}), \mathrm{V}$ is the chamber volume, $\mathrm{M}$ is the molar mass of methane $(16 \mathrm{~g} / \mathrm{mol}), \mathrm{U}$ is the units conversion factor $(0.00144 \mathrm{~L} \cdot \mathrm{min} / \mu \mathrm{L}$. day), $\mathrm{A}$ is the area covered by the chamber, $\mathrm{T}$ is the chamber temperature $(\mathrm{K}), \mathrm{R}$ is the gas constant $(0.08205 \mathrm{~L}$. atm $/ \mathrm{K} . \mathrm{mol})$, and $\mathrm{dc} / \mathrm{dt}$ is the slope of the linear regression between the gas concentrations over the elapsed time ( $\mathrm{ppm} / \mathrm{min})$.

The volume of the flux chamber $(\mathrm{V})=(0.910-0.60) *\left(\left(\frac{0.86}{2}\right)^{2}\right) * \pi=0.180 \mathrm{~m}^{3}=180 \mathrm{~L}$.

The area covered by the chamber $(\mathrm{A})=\pi^{*} \mathrm{r}^{2} \rightarrow \mathrm{A}=\pi^{*}(0.43)^{2}=0.58 \mathrm{~m}^{2}$.

\section{RESULTS AND DISCUSSION}

In this research, the experiments were conducted for a period of 16 weeks, and four primary reading values are taken once, every two weeks. During each test day, four primary readings are taken and the average value between the values is taken as the primary reading value. The interval between the four primary readings is five minutes.

\section{Methane Concentration Profile}

As illustrated in section 2.3, dc/dt is the slope of the linear regression between the gas concentrations over the elapsed time between the four primary readings that is five minutes. The outcome of the Gas Chromatograph regarding the analysis of LFG samples each test day are the concentration values of methane and carbon dioxide, a total of eight values (for both $\mathrm{CH}_{4}$ and $\mathrm{CO}_{2}$ ); with each two of the eight values representing a primary reading. Thus, we get four concentration values each test day, for methane and carbon dioxide.

For each test, the four methane concentration values were compared with their respective time intervals (five-minutes), in order to get the methane concentration profile. The methane concentration profile slope is used to acquire the $\mathrm{dc} / \mathrm{dt}$ value for each test day; the $\mathrm{dc} / \mathrm{dt}$ value takes the slope value. The regression coefficient $\left(\mathrm{R}^{2}\right)$ value is calculated from the plot, and we only obtain a non-zero flux value only if the linear regressions higher than 0.85 [13].Throughout the eight test days none of our values of the regression coefficient dropped below 0.85 .

The methane concentration profile for the first test day is shown in figure 5. The figure clarifies the slope and the regression coefficient values. The regression coefficient value was found to be 0.9542 which is higher than 0.85 , thus, this detects that the $\mathrm{dc} / \mathrm{dt}$ value is nonzero. The $\mathrm{dc} / \mathrm{dt}$ value was found to be 0.5 , which is the slope value.

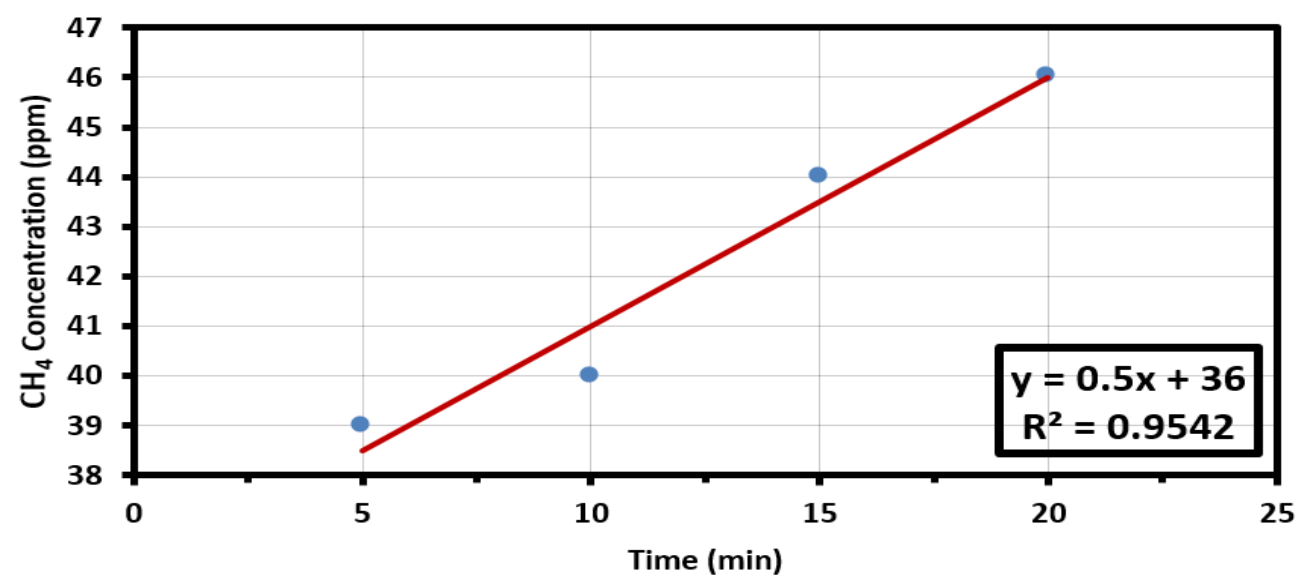

Figure 5. Methane concentration profile (first test day) 
The dc/dt values for each test day/two weeks are shown in table 2, which were then applied in the (FOD) model to get the methane emission values for each test day/two weeks. The dc/dt value's sign denotes either an increase, or a decrease in the methane concentration profile slope.

The methane emission values were used to design the methane emission potential table as demonstrated in section 3.1.1. Additionally, the resultant methane emission values were used to draw the methane emission profile rate, which is then compared with leachate $\mathrm{pH}$, waste moisture content and gas temperature in the following sections. The carbon dioxide concentration values were directly compared with time that is each test day/two weeks.

Table 2. dc/dt Values during the experiments.

\begin{tabular}{|c|c|c|}
\hline $\begin{array}{c}\text { Test } \\
\text { Day }\end{array}$ & $\begin{array}{c}\text { Time } \\
\text { (week) }\end{array}$ & dc/dt values \\
\hline 1 & 2 & 0.5 \\
\hline 2 & 4 & 0.58 \\
\hline 3 & 6 & 0.62 \\
\hline 4 & 8 & 0.7 \\
\hline 5 & 10 & 0.86 \\
\hline 6 & 12 & 0.76 \\
\hline 7 & 14 & -0.54 \\
\hline 8 & 16 & -0.44 \\
\hline
\end{tabular}

\section{Methane Emission Potential Table}

As demonstrated in section 2.3, the FOD model was used to estimate the methane emission from the bioreactor that is occupied with $250 \mathrm{~kg}$ of waste. The potential table can be further used to design a sanitary landfill and to get the energy outcome from it as a quantity. The LFG collected is considered as an energy source and can be used to minimize the use of the common energy sources [6]. The parameters used to calculate methane emission and their outcome each test day/two weeks are clarified in table 3.

Table 3. Methane emission potential table.

\begin{tabular}{|c|c|c|c|c|}
\hline $\begin{array}{c}\text { Test } \\
\text { Day }\end{array}$ & $\begin{array}{c}\text { Time } \\
\text { (week) }\end{array}$ & $\mathbf{T}\left({ }^{\circ} \mathbf{K}\right)$ & $\mathbf{d c / d t}$ & $\begin{array}{c}\mathbf{F} \\
\mathbf{g} / \mathbf{m}^{2} . \mathbf{d a y}\end{array}$ \\
\hline 1 & 2 & 310.65 & 0.5 & 0.14026 \\
\hline 2 & 4 & 306.5 & 0.58 & 0.16491 \\
\hline 3 & 6 & 303.95 & 0.62 & 0.17776 \\
\hline 4 & 8 & 302.957 & 0.7 & 0.20134 \\
\hline 5 & 10 & 301.75 & 0.86 & 0.24837 \\
\hline 6 & 12 & 301.15 & 0.76 & 0.21992 \\
\hline 7 & 14 & 300.9 & -0.54 & 0.15639 \\
\hline 8 & 16 & 300.675 & -0.44 & 0.12752 \\
\hline
\end{tabular}

\section{Methane Emission Profile}

The methane emission profile for each test day/two weeks is illustrated in figure 6. It was observed that the methane emission values encountered an increase during the first five test days, and then experienced a drop in the last three test days. 
At the beginning, the methane emission values kept increasing gradually as the leachate was circulated into the bioreactor, the rise peaked at approximately $0.25\left(\mathrm{~g} / \mathrm{m}^{2} . \mathrm{d}\right)$ on week $10 /$ fifth test day, denoting the end of the methanogenesis phase. After week 10, a drop occurred in the emission values reaching $0.12\left(\mathrm{~g} / \mathrm{m}^{2}\right.$. d)on week 16 denoting that the degradation process has finished (the oxidation phase ) [23].

The study proved that methane emission values increases with leachate circulation as stated in [21.24].

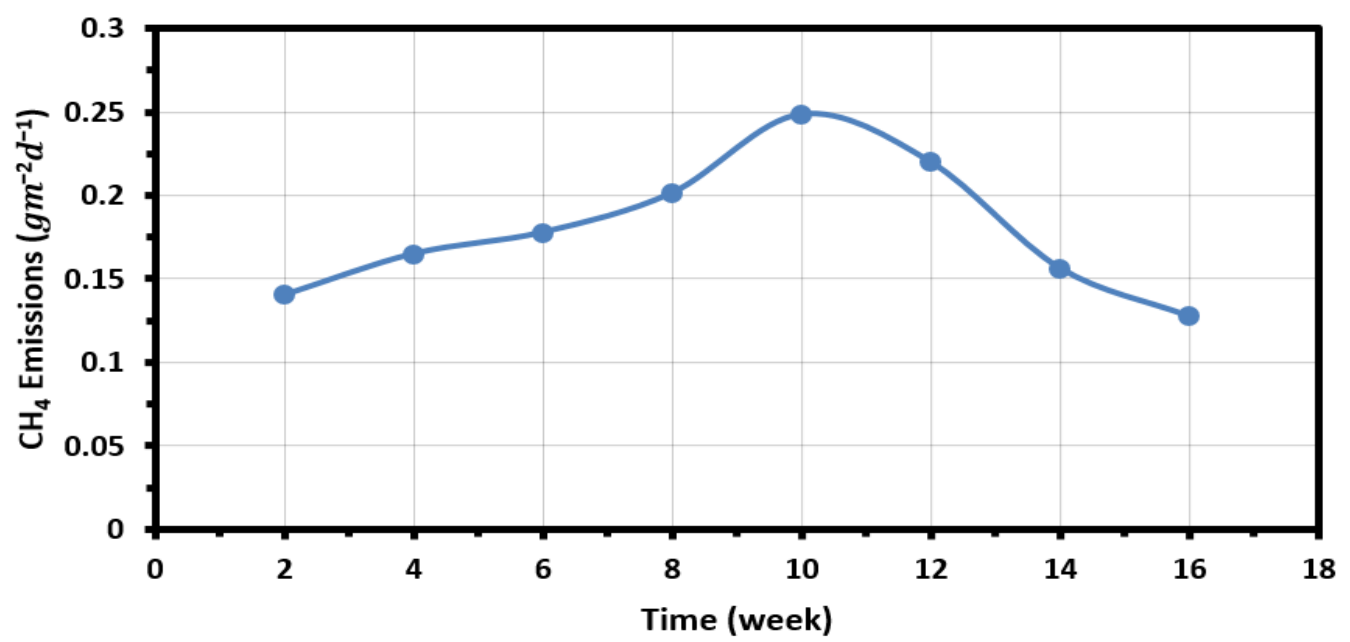

Figure 6. Methane emission rate profile

\section{Carbon Dioxide Concentration Profile}

The carbon dioxide concentration profile for each test day/two weeks is illustrated in figure 7. It was observed that the carbon dioxide concentration values encountered a decrease during the first six test days, and then experienced a slight increase in the last two test days.

As the methane concentration values kept increasing during the anaerobic phases, the carbon dioxide concentration values kept decreasing simultaneously, till the oxidation phase initiated, which initiated after week 10/fifth test day. The methane concentration values dropped, while the carbon dioxide concentration values increased reaching $48 \%$ on week 16 .

The study proved that methane concentration rate values are higher than carbon dioxide concentration rate values during the wet season, as the moisture content increases during the wet season. Similar observations are reported in [13].

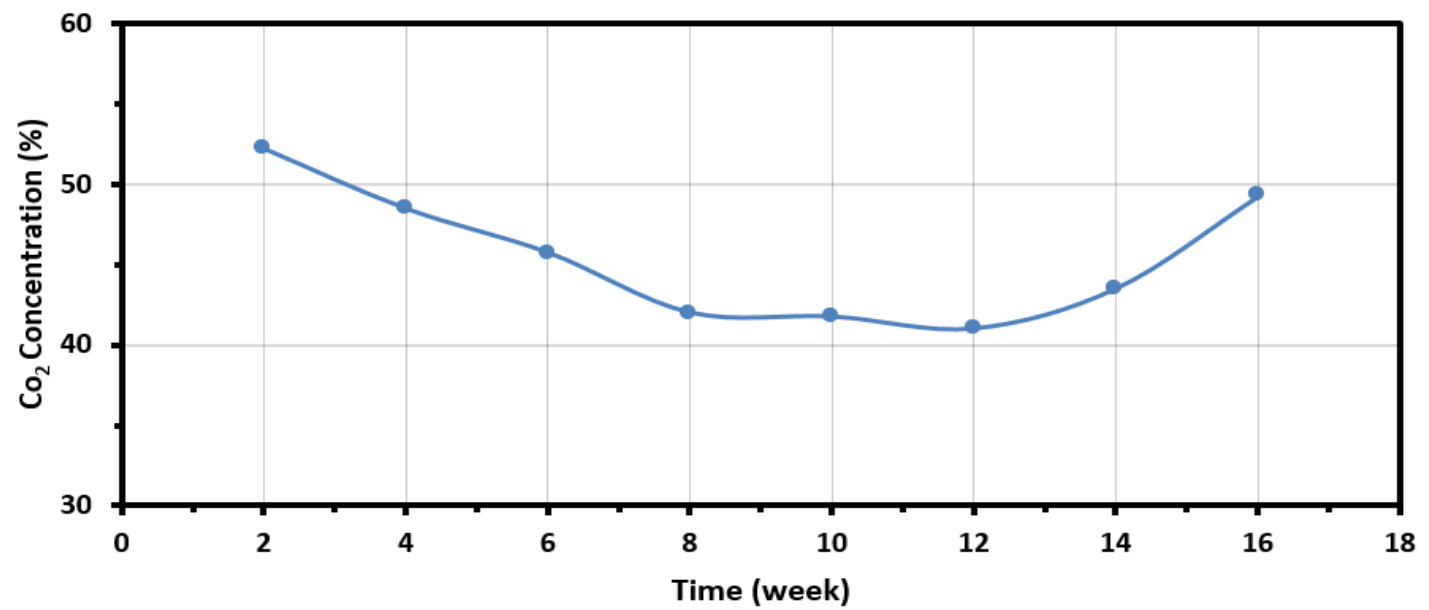

Figure 7. Carbon dioxide concentration rate profile 


\section{Methane Emissions Relationship with Leachate pH}

The academic work studied the contribution of leachate $\mathrm{pH}$ to change methane emission values in each test day/two weeks as illustrated in figure 8 .

It was observed that the methane emission values encountered an increase during the first five test days, and then experienced a drop in the last three test days, whilst, the leachate $\mathrm{pH}$ kept increasing throughout the study period.

The first leachate $\mathrm{pH}$ reading value was 6.9 , that is acidic, indicating the hydrolysis or aerobic degradation stage, in which the carbon dioxide absorbed in water caused the $\mathrm{pH}$ to be acidic. As the anaerobic degradation stages initiated, the organic acids were degraded by the methanogenic microorganisms, which caused the leachate $\mathrm{pH}$ to increase gradually reaching 7.95 on week $10 / 5^{\text {th }}$ test day. The leachate $\mathrm{pH}$ reading increased steadily during the oxidation stage, which occurred in the last three test days. Similar observations are reported in [23].

Additionally, the academic work studied the methane emission relationship with the leachate content in each test day/two weeks as illustrated in figure 9. It was observed that the leachate recirculation, even though it affected the methane emission values, caused a decrease in the leachate content. Similar observations are reported in [24].

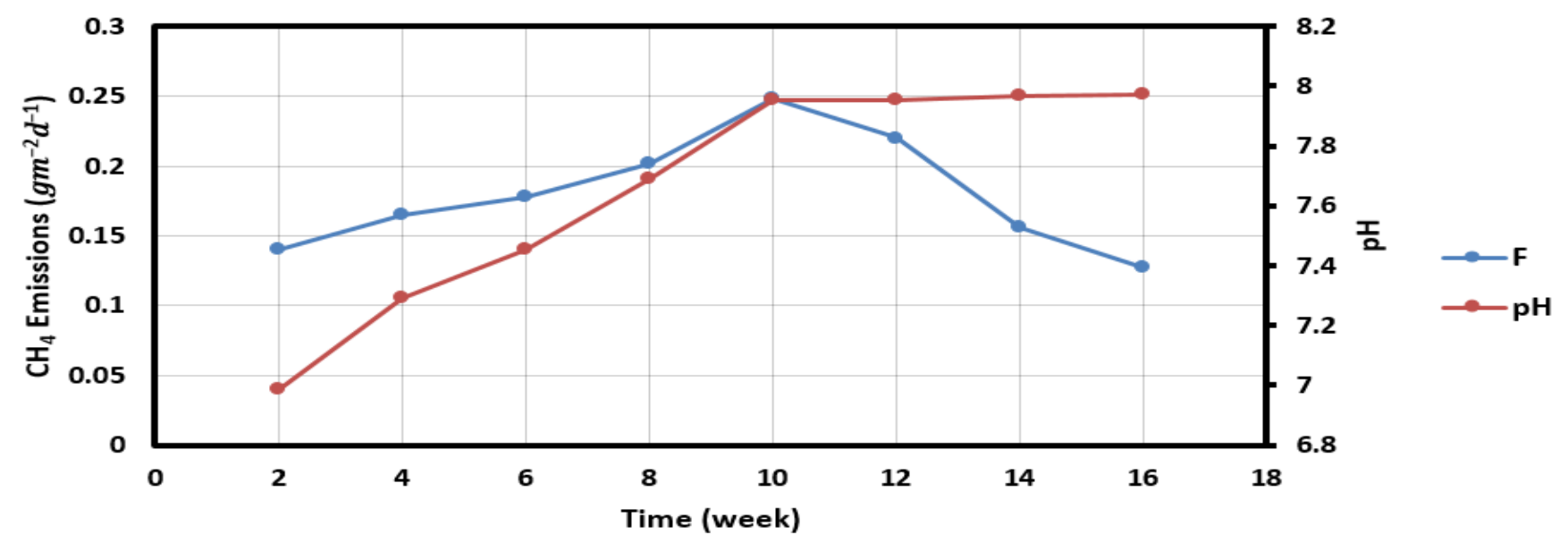

Figure 8. Methane emission rate vs. leachate $\mathrm{pH}$ rate.

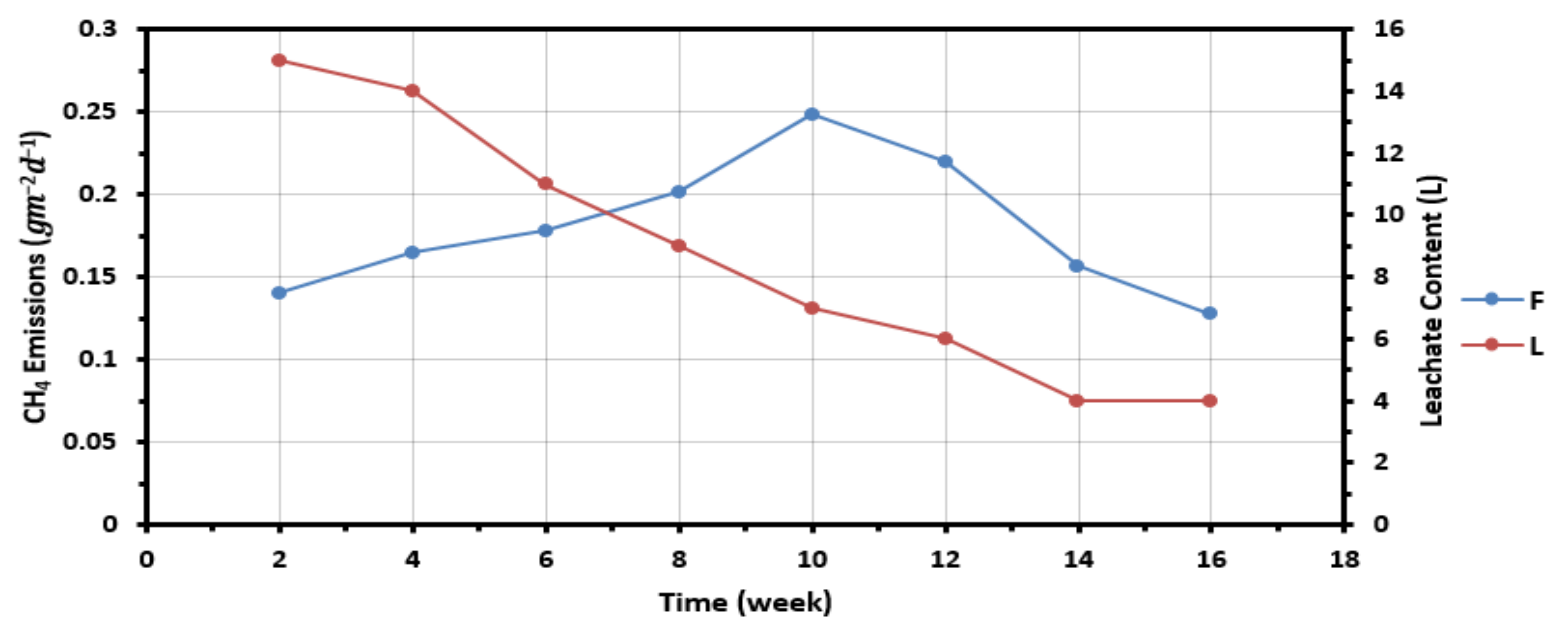

Figure 9. Methane emission rate vs. leachate content rate

\section{Methane Emissions Relationship with Waste Moisture Content}

The academic work studied the contribution of waste moisture content to change methane emission values in each test day/two weeks as illustrated in figure 10. It was observed that the methane emission values encountered 
an increase during the first five test days, and then experienced a drop in the last three test days, whilst, the waste moisture content kept increasing throughout the study period.

The leachate circulation process highly affected the waste moisture content, during the anaerobic stagesweek 2,4,6,8, and 10/test day 1 to 5; the waste moisture content increased gradually. However, as the oxidation phase initiated after week 10/fifth test day, the rate of increase in the moisture content decreased slightly. Similar observations are reported in [23].

The wet climate's high moisture content, and the food waste's wet environment were among the factors that led to an increase in waste moisture content during the study period.

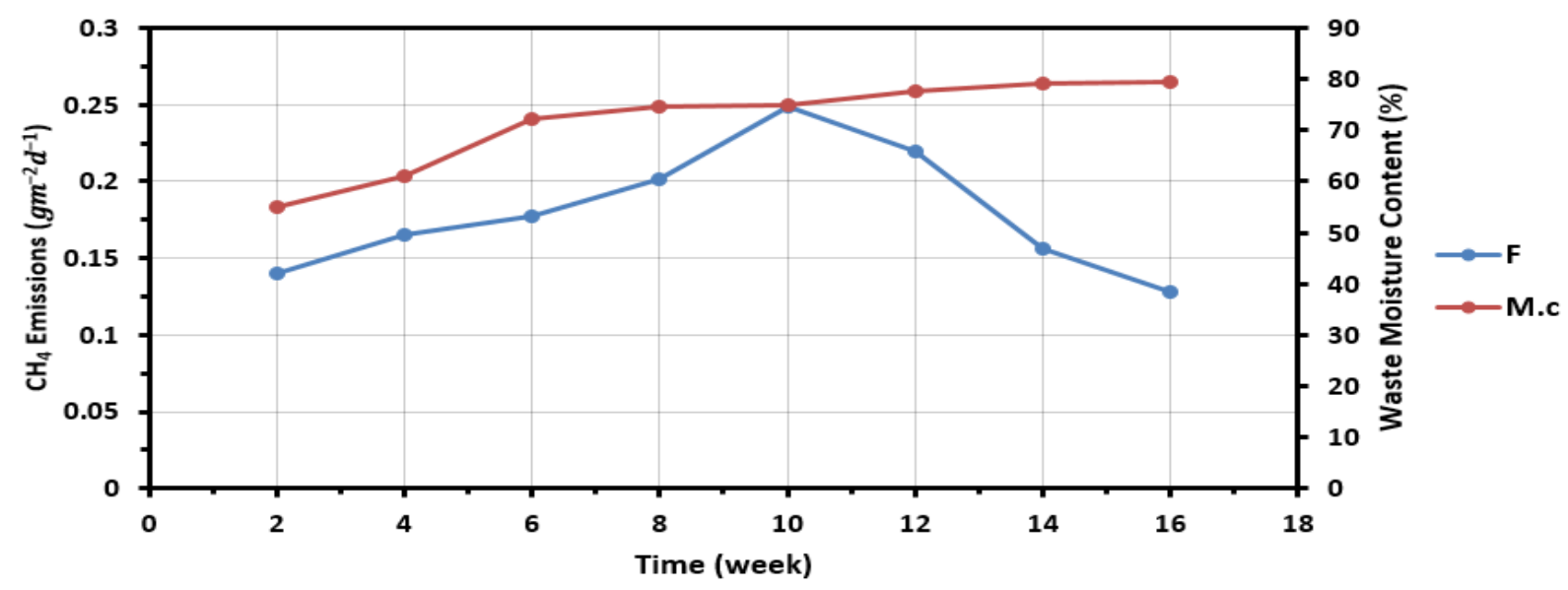

Figure 10. Methane emission rate vs. waste moisture content rate

\section{Methane Emission Rate Relationship with Gas Temperature}

The academic work studied the contribution of gas temperature to change methane emission values in each test day/two weeks as illustrated in figure 11. It was observed that the methane emission values encountered an increase during the first five test days, and then experienced a drop in the last three test days, whilst, the gas temperature kept decreasing throughout the study period.

According to the theoretical FOD model illustrated in section 2.3, the relationship between the gas temperature and methane emission is an indirect relationship. The study proved the model relationship between gas temperature and methane emission; the gas temperature kept decreasing through the whole degradation processes. The wet climate high moisture content and the shading tent were among the factors enhancing the decrease in gas temperature. Similar observations are reported in $[13,14]$.

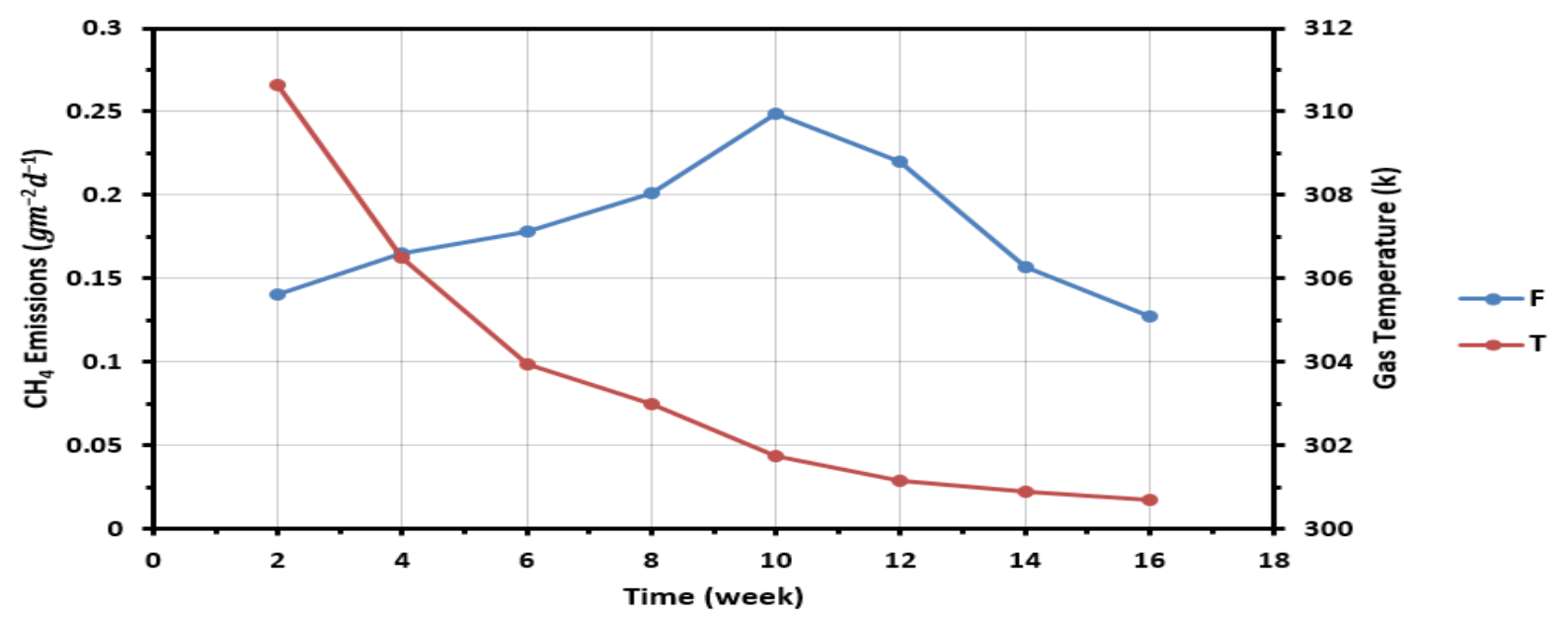

Figure 11. Methane emission rate vs. gas temperature rate 


\section{SEM Imaging}

The biomass characterization was established using the scanning electron microscopy imaging, and the conversion of waste to methane was related to the successful microbial population inside the bioreactor. figure 12 presents the biofilm imaging.

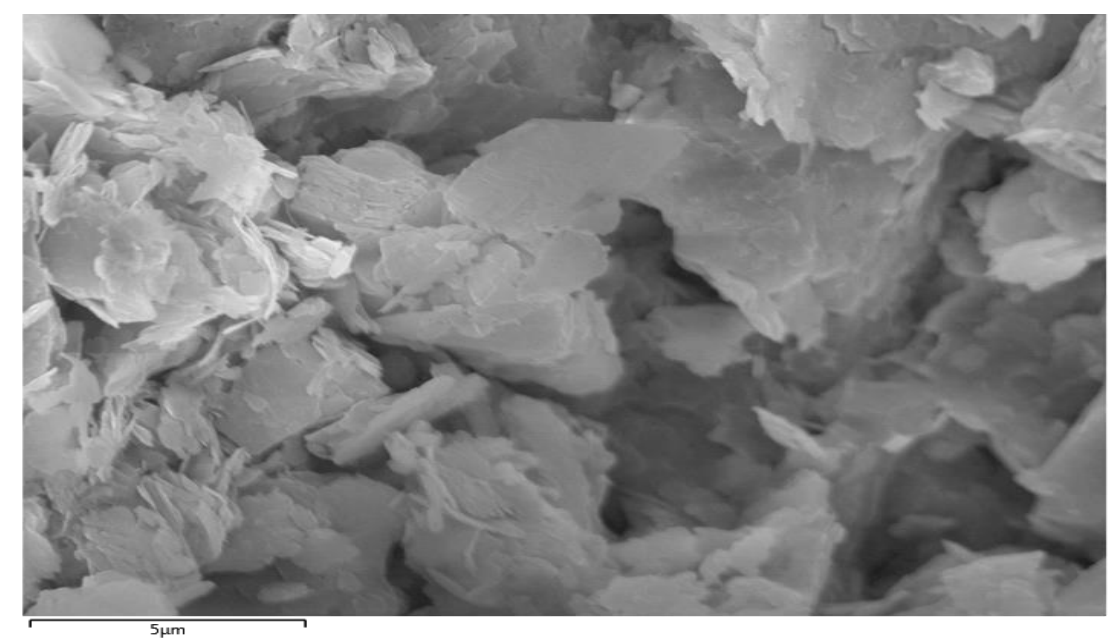

Figure 12. SEM image of biomass inside the bioreactor

\section{CONCLUSION}

This research work studied the feasibility of waste to biogas conversion in a sanitary landfill unit, using a static flux chamber and a pilot-scale sanitary landfill. The static flux chamber is applied on the pilot-scale sanitary landfill, and FOD is used to quantify the methane emission. $250 \mathrm{~kg}$ of waste was used in the bioreactor. The study illustrated that the methane emission rate peaked at $0.25 \mathrm{~g} / \mathrm{m}^{2}$. d during week 10 , and decreased to $0.12 \mathrm{~g} / \mathrm{m}^{2}$. $\mathrm{d}$ during week 16, and using these outcomes the methane emission potential table was established. Leachate circulation was found to have a positive effect on the methane emission values, however, the leachate content kept decreasing each test day as the leachate circulation process is initiated.

In addition, the carbon dioxide concentration and methane concentration rates obtained were $45 \%$, and 55\% respectively during the anaerobic phases, while carbon dioxide concentration and methane concentration rates obtained during the aerobic phases were $50 \%$, and $49 \%$ respectively, with a concentration percentage of less than one representing the other gases. This indicates that the carbon dioxide proportion will increase with time passing, concurrently, the methane concentration rate decreases. Additionally, the academic work studied the contribution of leachate $\mathrm{pH}$, waste moisture content, and gas temperature to change methane emission values. The research indicated that the alkalinity of leachate $\mathrm{pH}$ occurred after the anaerobic landfill phases started, as we know it was acidic during the first aerobic stage. The waste moisture content proved to have a direct relationship with the methane emission values. The research proved that methane emission values increases as the gas temperature decreases.

\section{NOMENCLATURE}

$\mathrm{Pvc}$

Fod

$\mathrm{P}$

$\mathrm{V}$

M

$\mathrm{U}$

A

$\mathrm{T}$

$\mathrm{R}$

$\mathrm{dc} / \mathrm{dt}$
Polyvinyl Chloride.

First order decay.

Pressure (1 Pa).

Chamber volume.

Molar mass of methane $(16 \mathrm{~g} / \mathrm{mol})$.

Units conversion factor (0.00144 L. min/ $\mu$ L. day).

Area covered by the chamber,

Chamber temperature (K).

Gas constant (0.08205 L. atm/K. mol).

Slope of the linear regression between the gas concentrations over the elapsed time ( $\mathrm{ppm} / \mathrm{min})$. 


\section{REFERENCES}

[1] Gan J, Sun Y, Sun W, Liu S. Computer simulation of moisture distribution in unlined aerobic bioreactor landfills—quasi-steady-state condition. Procedia Environmental Sciences. 2012 Jan 1;16:730-9.

[2] Chalermcharoenrat S, Laohalidanond K, Kerdsuwan S. Optimization of Combustion Behavior and Producer Gas Quality from Reclaimed Landfill Through Highly Densify RDF-Gasification. Energy Procedia. 2015 Nov 1;79:321-6.

[3] Bo-Feng C, Jian-Guo L, Qing-Xian G, Xiao-Qin N, Dong C, Lan-Cui L, Ying Z, Zhan-Sheng Z. Estimation of methane emissions from municipal solid waste landfills in China based on point emission sources. Advances in Climate Change Research. 2014 Jan 1;5(2):81-91.

[4] Fallahizadeh S, Rahmatinia M, Mohammadi Z, Vaezzadeh M, Tajamiri A, Soleimani H. Estimation of methane gas by LandGEM model from Yasuj municipal solid waste landfill, Iran. MethodsX. 2019 Jan $1 ; 6: 391-8$.

[5] Dace E, Blumberga D, Kuplais G, Bozko L, Khabdullina Z, Khabdullin A. Optimization of landfill gas use in municipal solid waste landfills in Latvia. Energy Procedia. 2015 Jun 1;72(Jun):293-9.

[6] Das D, Majhi BK, Pal S, Jash T. Estimation of land-fill gas generation from municipal solid waste in Indian Cities. Energy Procedia. 2016 Dec 1;90:50-6.

[7] Miezah K, Obiri-Danso K, Kádár Z, Fei-Baffoe B, Mensah MY. Municipal solid waste characterization and quantification as a measure towards effective waste management in Ghana. Waste Management. 2015 Dec $1 ; 46: 15-27$.

[8] Emmi G, Zarrella A, Zuanetti A, De Carli M. Use of municipal solid waste landfill as heat source of heat pump. Energy Procedia. 2016 Nov 1;101:352-9.

[9] Al-Wabel MI, Al Yehya WS, Al-Farraj AS, El-Maghraby SE. Characteristics of landfill leachates and biosolids of municipal solid waste (MSW) in Riyadh City, Saudi Arabia. Journal of the Saudi Society of Agricultural Sciences. 2011 Jun 1;10(2):65-70.

[10] Raghab SM, Abd El Meguid AM, Hegazi HA. Treatment of leachate from municipal solid waste landfill. HBRC journal. 2013 Aug 1;9(2):187-92.

[11] PK A, Anilkumar PP. Development of landscaped landfills using organic waste for sustainable urban waste management. Procedia Environmental Sciences. 2016;35:368-76.

[12] Moya D, Aldás C, López G, Kaparaju P. Municipal solid waste as a valuable renewable energy resource: a worldwide opportunity of energy recovery by using Waste-To-Energy Technologies. Energy Procedia. 2017 Oct 1;134:286-95.

[13] Abushammala MF, Basri NE, Younes MK. Seasonal variation of landfill methane and carbon dioxide emissions in a tropical climate. International Journal of Environmental Science and Development. 2016 Aug 1;7(8):586.

[14] Abushammala MF, Basri NE, Basri H, Kadhum AA, El-Shafie AH. Methane and carbon dioxide emissions from Sungai Sedu open dumping during wet season in Malaysia. Ecological Engineering. 2012 Dec 1;49:254-63.

[15] Jeong S, Park J, Kim YM, Park MH, Kim JY. Innovation of flux chamber network design for surface methane emission from landfills using spatial interpolation models. Science of the total environment. 2019 Oct 20;688:18-25.

[16] Fauziah SH, Izzati MN, Agamuthu P. Toxicity on Anabas Testudineus: a case study of sanitary landfill leachate. Procedia Environmental Sciences. 2013 Jan 1;18:14-9.

[17] Sudibyo H, Shabrina ZL, Halim L, Budhijanto W. Mathematical modelling and statistical approach to assess the performance of anaerobic fixed bed reactor for biogas production from Piyungan Sanitary Landfill leachate. Energy Procedia. 2017 May 1;105:256-62.

[18] Palanivel TM, Sulaiman H. Generation and composition of municipal solid waste (MSW) in Muscat, Sultanate of Oman. APCBEE procedia. 2014 Jan 1;10(2014):96-102.

[19] Hereher ME, Al-Awadhi T, Mansour SA. Assessment of the optimized sanitary landfill sites in Muscat, Oman. The Egyptian Journal of Remote Sensing and Space Science. 2019 Aug 9. 
Journal of Thermal Engineering, Research Article, Vol. 6, No. 6, Special Issue 12, pp. 298-311, December 2020

[20] Engineers, U. A.LANDFILL GAS COLLECTION AND TREATMENT SYSTEMS. Washington, DC: DEPARTMENT OF THE ARMY U.S. Army Corps of Engineers (2013).

[21] Agency, U. S.BIOREACTOR PERFORMANCE SUMMARY PAPER U.S. EPA Office of Solid Waste, Municipal and Industrial Solid Waste Management Division. USEPA (2007).

[22] USEPA.GUIDANCE FOR EVALUATING LANDFILL GAS EMISSIONS FROM CLOSED OR ABANDONED FACILITIES. Washington, DC: U.S. Environmental Protection Agency Office of Research and Development. (2005)

[23] T.Williams, P. Waste Treatment and Disposal second edition. Leeds: John Wiley \& Sons (2005).

[24] Zhao, Y., \& Lou, Z. POLLUTION CONTROL AND RESOURCE RECOVERY, Municipal Solid Wastes at Landfill. SHANGHAI: Butterworth-Heinemann (2017).

[25] Davis, M. L., \& Cornwell, D. A. Introduction to Environmental Engineering Fourth Edition. McGraw-Hill (2008).

[26] Davis, M. L., \& Cornwell, D. A. Introduction To Environmental Engineering Fifth Edition. New York: McGraw-Hill (2013). 